\title{
A silicon carbide thermistor
}

\author{
N.S. Boltovets ${ }^{1}$, V.V. Kholevchuk ${ }^{2}$, R.V. Konakova ${ }^{2}$, Ya.Ya. Kudryk ${ }^{2}$, P.M. Lytvyn ${ }^{2}$, \\ V.V. Milenin', V.F. Mitin', E.V. Mitin² \\ ${ }^{I}$ State Enterprise Research Institute "Orion”, 8a, Eugene Pottier str., 03057 Kyiv, Ukraine \\ ${ }^{2} V$. Lashkaryov Institute of Semiconductor Physics, NAS of Ukraine, \\ 41, prospect Nauky, 03028 Kyiv, Ukraine \\ Phone:(380-44) 525-61-82; fax: (380-44) 525-83-42 \\ E-mail: konakova@isp.kiev.ua
}

Abstract. We consider a silicon carbide thermistor with multilayer $\mathrm{Au}-\mathrm{TiB}_{x}-\mathrm{Ni}_{2} \mathrm{Si}$ ohmic contacts intended for operation in the 77 to $450 \mathrm{~K}$ temperature range.

Keywords: silicon carbide, thermistor, ohmic contact, buffer layer.

Manuscript received 04.10.06; accepted for publication 23.10.06.

\section{Introduction}

Silicon carbide $(\mathrm{SiC})$ is a promising material for device applications (in particular, those involving arduous environmental conditions), and its thermal and radiation resistances are well documented. The $\mathrm{SiC}$ devices are usually used for extreme electronics when high temperatures and intense radiation are present.

The main subject of this work was the implementation of $\mathrm{SiC}$ for development of a highly sensitive thermometer capable for use from liquid nitrogen temperatures up to $450 \mathrm{~K}$ and in the presence of ionizing radiation.

It is well known that the radiation and thermal tolerances of semiconductor devices strongly depend on their design and the material properties, especially on the radiation and thermal resistances of the electrical contacts to the semiconductor elements. The preparation of reliable ohmic metal contacts to semiconductors operating at high temperatures or under radiation presents a difficult materials science problem. In the course of operation both under high radiation and in high temperature environment, the main mechanism of contact degradation is due to the mass transfer from the metal layer into the semiconductor element structure. The process of contact degradation may change the resistance and thermal sensitivity of sensors. Usually structure defects which are also produced by radiation in doped semiconductors have a small effect on the thermal sensor properties; they can strongly affect the sensor properties only after very high dose of irradiation.

The ohmic contacts must therefore be chemically and physically compatible with the thermo-sensitive material over the operating temperature range and have similar resistance to the measurement environment of the thermometer. In the case of SiC thermometers, the formation of such contacts makes a considerable physico-technological problem since many of the metallic materials which are traditionally used as ohmic contacts form carbides and silicides when interacting with $\mathrm{SiC}$, thus leading to nonuniform metal-SiC interfaces. As a result, the contacts are degrading in the course of operation at high temperatures. The degradation processes result in mass transfer of gold from the metallization layer into $\mathrm{SiC}$ through nonuniform metallic phase layers in the ohmic contact.

Here we present our results on development of a $\mathrm{SiC}$ thermistor with multilayer $\mathrm{Au}-\mathrm{TiB}_{x}-\mathrm{Ni}_{2} \mathrm{Si}$ ohmic contacts. A buffer layer $\left(\mathrm{TiB}_{x}\right)$ was formed between the upper $(\mathrm{Au})$ metallization layer and metal layer $\left(\mathrm{Ni}_{2} \mathrm{Si}\right)$ forming the ohmic contact. This buffer layer is made by a quasi-amorphous nanocrystalline $\mathrm{TiB}_{x}$ phase that prevents mass transfer in contacts.

\section{Sample preparation and experimental procedures}

In our experiments, we used Lely-grown $\mathrm{SiC}$ single crystals of $n$-type (polytype 21R). The concentration of non-compensated donors was $\sim 1.2 \cdot 10^{18} \mathrm{~cm}^{-3}$. After chemical treatment of surface, nickel layers (thickness of $200 \mathrm{~nm}$ ) were deposited onto both $\mathrm{SiC}$ faces by using magnetron sputtering. Then these layers were fired at the temperature $T=1000^{\circ} \mathrm{C}$ for $90 \mathrm{~s}$. After this, using magnetron sputtering, we deposited layers of $\mathrm{TiB}_{x}$ $(100 \mathrm{~nm}$ thick) and gold (200 nm thick) onto the ohmic contacts formed by the above way. The gold layer was then developed up to a thickness of $3 \mu \mathrm{m}$ with electroplating. The scribed chips (area of $0.5 \times 0.5 \mathrm{~mm}^{2}$ ) 
were mounted into packages. After this, we took the thermometric characteristics of thermistors in the 77-450 K temperature range.

Both before and after metal-SiC structure firing, we measured (i) metal-SiC contact resistance of the test structures obtained and (ii) concentration depth profiles of contact components using the Auger electron spectroscopy (AES). Phase composition of the ohmic contacts was determined with X-ray diffraction (XRD) technique. The thermometric characteristics of the $\mathrm{Au}-$ $\mathrm{TiB}_{x}-\mathrm{Ni}_{2} \mathrm{Si}-n-21 \mathrm{R}-\mathrm{SiC}$ system were measured within the $77-450 \mathrm{~K}$ temperature range.

\section{Results and discussion}

\section{A. Characterization of $\mathrm{Au}-\mathrm{Ti} B_{x}-\mathrm{Ni}-21 \mathrm{R}-\mathrm{SiC}$ contacts}

For the $\mathrm{Au}-\mathrm{TiB}_{x}-\mathrm{Ni}-21 \mathrm{R}-\mathrm{SiC}$ test structures, we measured the Auger component concentration depth profiles in the metallization layers and at the $\mathrm{Ni}-n-21 \mathrm{R}-$ $\mathrm{SiC}$ interface, both before and after rapid thermal annealing (RTA) at $1000{ }^{\circ} \mathrm{C}$ (Fig. 1a, b). One can see from Fig. 1a that the initial sample retains the layered metallization structure, and the Ni-n-21R-SiC interface has a junction region formed with the components of the semiconductor and $\mathrm{TiB}_{x}$ (whose composition is close to $\mathrm{TiB}_{2}$ ). According to the data from literature [1], one can assume that the junction region at the $\mathrm{Ni}-n-21 \mathrm{R}-\mathrm{SiC}$ interface is formed with the low-temperature nickel silicide phases. (This contact region is considered in more detail in the subsection B.)

No considerable changes occurred in the $\mathrm{Au}$ and $\mathrm{TiB}_{2}$ layers after RTA at $T=1000^{\circ} \mathrm{C}$. The contactforming Ni layer, however, changed its structure due to reaction with $\mathrm{SiC}$.

A comparison between the metallization component concentration depth profiles taken before and after RTA showed that the $\mathrm{TiB}_{2}$ layer demonstrates buffer properties. In the course of RTA at $T=1000^{\circ} \mathrm{C}$, $\mathrm{TiB}_{2}$ practically did not react with the contact-forming layer formed with nickel silicides. The $\mathrm{Au}-\mathrm{TiB}_{2}$ interface became slightly wider due to Au mass transfer.

Our investigations of $I-V$ curves of the $\mathrm{Au}-\mathrm{TiB}_{x}$ $\mathrm{Ni}-n-21 \mathrm{R}-\mathrm{SiC}$ contacts taken before and after RTA showed that the initial samples demonstrated barriertype $I-V$ curves [2], while those after RTA had ohmictype $I-V$ curves (with $\rho_{c} \leq 10^{-3} \mathrm{Ohm} \cdot \mathrm{cm}^{2}$ ).

The mechanism of ohmic contact formation at RTA, as well as the properties of the interface between $\mathrm{Ni}$ (and its silicide phases) and $\mathrm{SiC}$, were studied for specially made test structures.

\section{B. Characterization of $\mathrm{Ni}\left(\mathrm{Ni}_{2} \mathrm{Si}\right)-n-21 \mathrm{R}-\mathrm{SiC}$ interface and ohmic contact}

Our studies of $I-V$ curves of the initial $\mathrm{Ni}-n-21 \mathrm{R}-\mathrm{SiC}$ contact structures showed that the $I-V$ curves were of the barrier type. However, the Schottky barrier height $\varphi_{B}$ was lower than that in contacts formed with $\mathrm{Ni}$ by 0.2 to
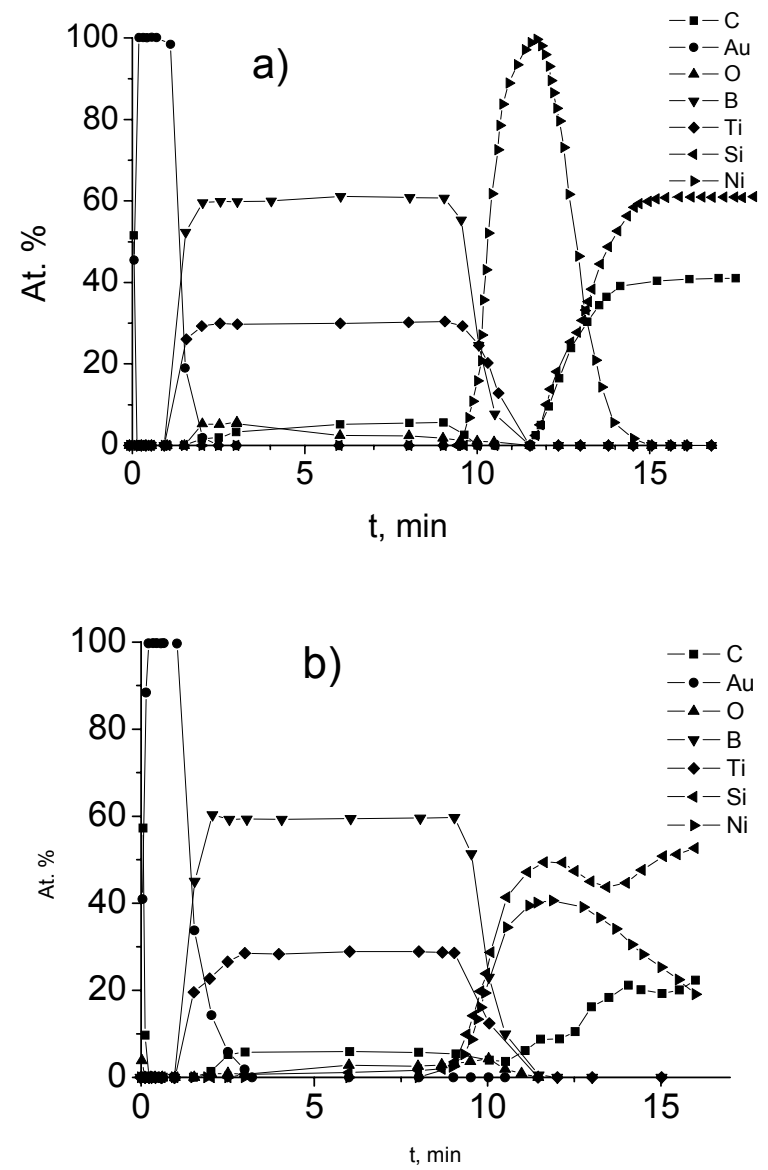

Fig. 1. Auger concentration depth profiles of $\mathrm{Au}-\mathrm{TiB}_{\mathrm{x}}-\mathrm{Ni}-$ $n$-SiC contact components before (a) and after RTA (b) at $1000^{\circ} \mathrm{C}$.

$0.3 \mathrm{~V}$. This fact indicates that (i) the initial contact structures involved nickel silicide phases whose work function is less than that of nickel (see [3]), and (ii) due to magnetron sputtering of nickel, the $\mathrm{SiC}$ substrate was heated up to temperatures $\left(\sim 250 \ldots 300^{\circ} \mathrm{C}\right)$ at which silicide phases are produced (though it was not heated specially).

The above results agree with those obtained with XRD - see Fig. 2, curve 1 for the (0001) face. One can see from Fig. 2 that, even in the initial contact structure, the phases $\mathrm{NiSi}, \delta-\mathrm{Ni}_{2} \mathrm{Si}$ and $\mathrm{NiSi}_{2}$ are present, along with pure $\mathrm{Ni}$. A comparison between the component concentration depth profiles in the initial contacts (Fig. 3a) and phase composition of the contact-forming layer shows that an extended region is formed in the $\mathrm{Ni}-n-21 \mathrm{R}-\mathrm{SiC}$ contact on the (0001) face. This fact indicates formation of $\mathrm{Ni}-\mathrm{Si}$ chemical bonds due to substrate heating up (even at the metal adsorption stage). It is in agreement with the data on temperatures of phase formation for various nickel silicides [4], as well as correlates with the XRD results obtained for the same samples. 


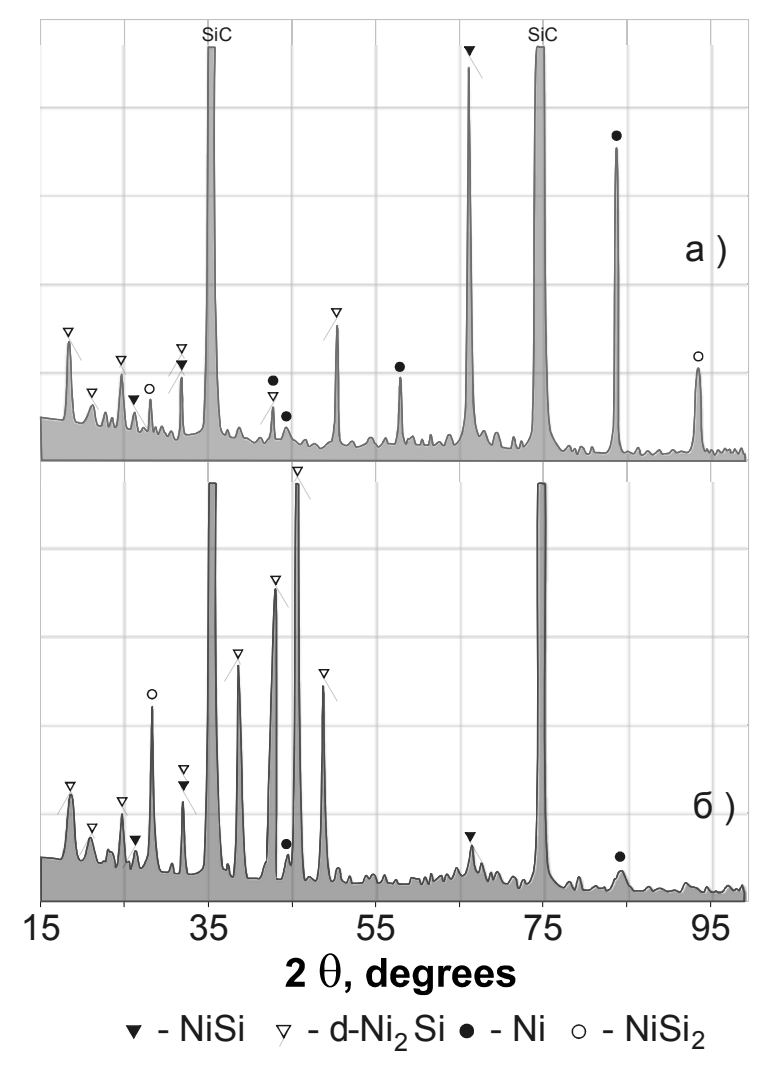

Fig. 2. XRD pattern for $\mathrm{Ni}-n-21 \mathrm{R}-\mathrm{SiC}$ samples before (a) and after RTA (b) at $1000{ }^{\circ} \mathrm{C}$.

RTA of the test structures at $T=1000{ }^{\circ} \mathrm{C}$ leads to formation of ohmic contacts with the reduced $\left(\leq 10^{-3} \mathrm{Ohm} \cdot \mathrm{cm}^{2}\right)$ contact resistivity $\rho_{c}$. It follows from the XRD data (Fig. 2, curve 2) that, due to RTA, practically total (not bonded chemically) nickel has interacted with $\mathrm{SiC}$. In this case, the $\delta-\mathrm{Ni}_{2} \mathrm{Si}$ phase was formed whose fraction increased as compared to that in the initial sample. The above results are also supported by the results on the Auger concentration depth profiles of contact components after RTA (Fig. 3b), which indicates at intense silicide formation over the total metal layer thickness. Repeated RTA at $T=1000{ }^{\circ} \mathrm{C}$ did not lead to considerable changes in both the parameters and composition of the $\mathrm{Ni}_{2} \mathrm{Si}-\mathrm{SiC}$ interface.

An analysis of $I-V$ curves at small biases was made for the contact structures after RTA. It showed that the Schottky barrier height decreased considerably and was $0.3 \ldots 0.32 \mathrm{~V}$ (for different samples), the ideality factor being $\sim 1.38 \ldots 1.4$. This indicates the thermionic mechanism for current flow in contact. In this case, according to the thermionic emission model, the reduced contact resistance can be calculated from the following expression:

$\rho_{c}=\frac{k}{q A^{*} T} \exp \left(\frac{q \varphi_{B}}{k T}\right)$
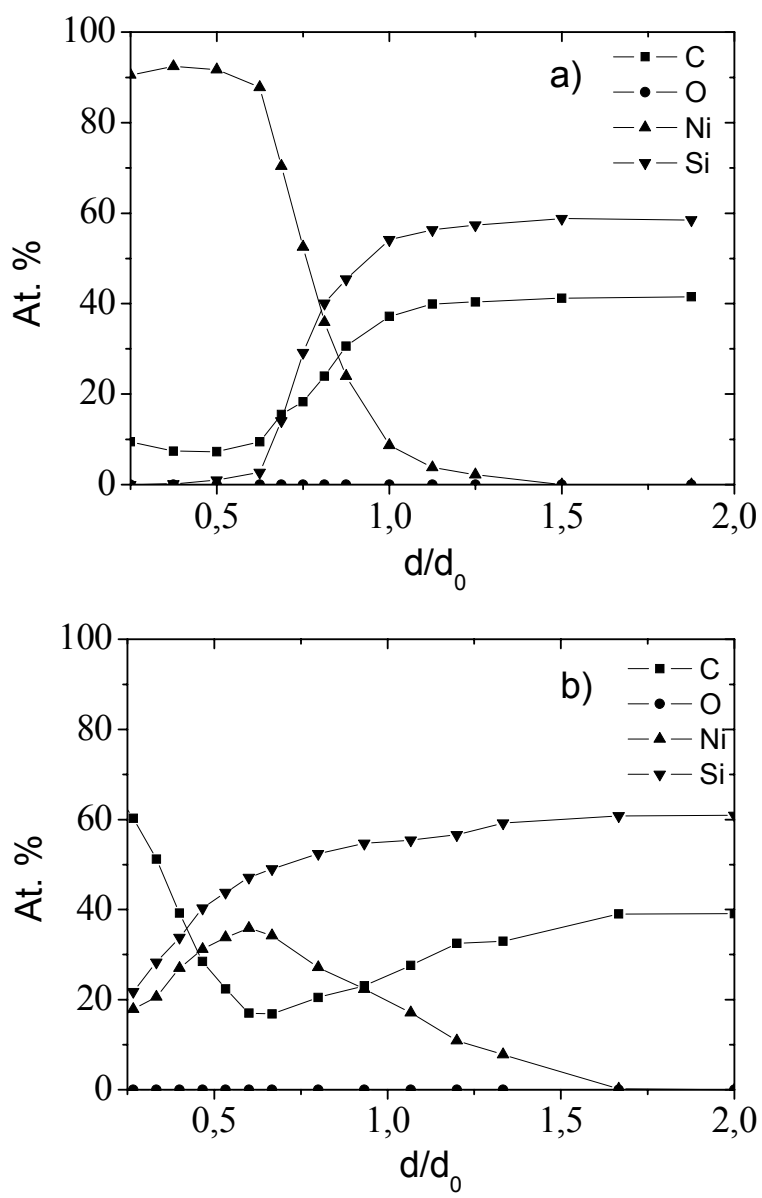

Fig. 3. Auger concentration depth profiles of $\mathrm{Ni}-n-21 \mathrm{R}-\mathrm{SiC}$ contact components before (a) and after RTA (b) at $1000{ }^{\circ} \mathrm{C}$.

where $k$ is the Boltzmann constant, $q$ is the electron charge and $A^{*}$ is the Richardson constant.

At $\varphi_{B} \approx 0.32 \mathrm{~V}(0.3 \mathrm{~V})$, the $\rho_{c}$ value is $\sim 9 \cdot 10^{-4} \mathrm{Ohm} \cdot \mathrm{cm}^{2}\left(\sim 4 \cdot 10^{-4} \mathrm{Ohm} \cdot \mathrm{cm}^{2}\right)$. These results are in agreement with the typical values [5] for the contact resistance in the $\mathrm{Ni}_{2} \mathrm{Si}-n$-SiC structures, as well as with our data obtained from direct measurements of $\rho_{c}$. It should be noted that for some contact structures after RTA, linear $I-V$ curves were observed, with $\rho_{c} \approx$ $\approx 10^{-3} \ldots 10^{-4} \mathrm{Ohm} \cdot \mathrm{cm}^{2}$. The distinction in current flow mechanisms in the $\mathrm{Ni}_{2} \mathrm{Si}-n-21 \mathrm{R}-\mathrm{SiC}$ contact structures seems to be due to inhomogeneous phase composition of metallization. This conclusion is supported by the XRD results for these samples (see Fig. 2).

\section{Thermometric characteristics of the thermistor made on the basis of $n-21 R-S i C$}

The size of $\mathrm{SiC}$ thermistor chips produced was $0.5 \mathrm{~mm}$ square by $0.4 \mathrm{~mm}$ thick. They were packaged in cylindrical canister packages, $3 \mathrm{~mm}$ in diameter and $5 \mathrm{~mm}$ long. 


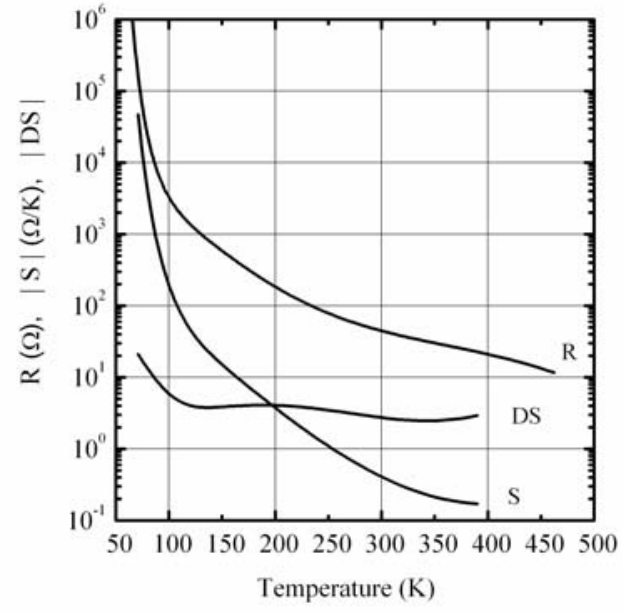

Fig. 4. Typical resistance $(R)$, sensitivity $(S)$ and dimensionless sensitivity $(D S)$ versus temperature curves for $n$-21R-SiC-bulk resistance thermometers.

Fig. 4 shows typical thermometric characteristics of the $\mathrm{Au}-\mathrm{TiB}_{x}-\mathrm{Ni}_{2} \mathrm{Si}-n-21 \mathrm{R}-\mathrm{SiC}$ thermistors, namely, the temperature dependence of resistance $R$, temperature sensitivity $S=d R / d T$, and dimensionless sensitivity, $S_{d}=$ $=(T / R)(d R / d T)$, over the temperature range from $\sim 77$ up to $450 \mathrm{~K}$. The thermistor shows very high sensitivity, changing resistance by $10^{5}$ times (from $10^{6}$ down to $10 \mathrm{Ohm}$ ) in the temperature range from 77 up to $450 \mathrm{~K}$. Further investigations are aimed at widening the operating temperature range of the $\mathrm{Au}-\mathrm{TiB}_{x}-\mathrm{Ni}_{2} \mathrm{Si}-n$ $21 \mathrm{R}-\mathrm{SiC}$ thermistors to both low and high temperatures.

\section{Conclusion}

Our investigations have shown that the $\mathrm{Au}-\mathrm{TiB}_{x}-\mathrm{Ni}_{2} \mathrm{Si}$ multilayer contact system is promising for the production of $\mathrm{SiC}$ resistance thermometers having improved reliability when operating for extended periods at elevated temperatures. The thermistor developed on the basis of $\mathrm{Au}-\mathrm{TiB}_{x}-\mathrm{Ni}_{2} \mathrm{Si}-n-21 \mathrm{R}-\mathrm{SiC}$ structures is very promising for highly sensitive temperature measurements in the 77 to $450 \mathrm{~K}$ temperature range.

\section{References}

1. O.A. Agueev, The technological problems of contacts to silicon carbide, TRTU Publishers, Taganrog, 2005 (in Russian).

2. S.P. Avdeev, O.A. Agueev, R.V. Konakova, Ya.Ya. Kudryk, O.S. Lytvyn, V.V. Milenin, D.A. Sechenov, A.M. Svetlichnyi, Modification of the parameters of metal-silicon carbide contacts using pulsed thermal treatment // Fizika i khimiya obrabotki materialov No 6, p. 84-88, 2004 (in Russian).

3. V.S. Fomenko, Emission properties of materials (Handbook). Naukova Dumka, Kiev, 1981 (in Russian).

4. S.P. Murarka, Silicides for VLSI Application. Academic Press, New York-London, 1983.

5. F. Roccaforte, Processes for SiC devices: new trends in metallization, in $5^{\text {th }}$ European Conf. on Silicon Carbide and Related Materials (ECSCRM 2004) Tutorial, v.1, Bologna, Italia. 